\title{
Gender and Sexual Diversity in Asian Universities
}

Khoo Hoon Eng and Daryl W. J. Yang

\section{INTRODUCTION}

In January 2016, Indonesia's Technology, Research and Higher Education Minister Muhammad Nasir called for lesbian, gay, bisexual, transgender, and questioning (LGBTQ) students to be banned from university campuses in the country. ${ }^{1} \mathrm{He}$ was responding to reports that an informal group known as the Support Group and Resource Center on Sexuality Studies (SGRC) at the University of Indonesia (UI) had been allowed to provide counselling for LGBTQ students and advocate for the LGBTQ

1 "LGBT Not Welcome at University: Minister," The Jakarta Post, January 25, 2016, https://www.thejakartapost.com/news/2016/01/25/lgbt-not-welcomeuniversity-minister.html.

K. H. Eng · D. W. J. Yang $(\bowtie)$

Yale-NUS College, Singapore, Singapore

e-mail: darylyang@u.yale-nus.edu.sg

K. H. Eng

e-mail: hooneng.khoo@yale-nus.edu.sg

(C) The Author(s) 2020

C. S. Sanger and N. W. Gleason (eds.),

Diversity and Inclusion in Global Higher Education, https://doi.org/10.1007/978-981-15-1628-3_9 
community. In response, the university's Rector clarified that SGRC was not an official group recognized by the university.

Elsewhere, in Japan, a male graduate student from the law faculty at Hitotsubashi University committed suicide after his sexual orientation was made public against his will in August 2015. ${ }^{2}$ A year after his death, two students from the same university started a student group to foster a safe space for LGBTQ students on campus; the group was officially recognized by the university in May $2017 .^{3}$

These two examples from Indonesia and Japan demonstrate firstly, the serious challenges that continue to face LGBTQ university students across Asia and secondly, the different institutional approaches toward LGBTQ diversity and inclusion in the region that largely ranges from hostility to ambivalence. Often, affirming institutions are either found in societies that have never criminalized same-sex sexual acts, such as Taiwan, Thailand, and the Philippines, or have some Anglo-American affiliation as in the case of New York University's satellite campuses in Shanghai and Abu Dhabi or Yale-NUS College, the product of a collaboration between Yale University and the National University of Singapore. In rare instances, universities in more hostile environments, such as the Jakarta Theological Seminary in the capital city of Indonesia, have sought to adopt an affirming approach toward LGBTQ diversity despite public and political opposition. ${ }^{4}$

It is unsurprising that most Asian universities are not affirming of LGBTQ diversity. A significant proportion of countries that still criminalize consensual same-sex sexual acts are located in Asia and most Asian countries still have yet to introduce any legislative or policy measure to

\footnotetext{
${ }^{2}$ Nagayasu Shibun, "Sexual Minorities in Japan: The Myth of Tolerance," Nippon.com, October 21, 2016, https://www.nippon.com/en/currents/d00253/.

3 "2 Students form Social Group for Sexual Minorities at Hitotsubashi Univ. After Suicide," The Mainichi, February 28, 2019, https://mainichi.jp/english/articles/ 20190228/p2a/00m/0na/004000c.

${ }^{4}$ Eduard Merigo, "In Indonesia, LGBT Communities Viewed as Moral ThreatCondemned by Religion, and Increasingly, by Law," South China Morning Post, April 7, 2019, https://www.scmp.com/magazines/post-magazine/long-reads/article/ 3004634/indonesia-lgbt-community-viewed-moral-threat.
} 
protect LGBTQ persons from discrimination or violence. ${ }^{5}$ This is exacerbated by the stigma and prejudice against LGBTQ individuals that permeate some Asian societies because gender and sexual diversity are viewed negatively for historical, religious, and political reasons. This contributes to an unwelcoming and sometimes hostile environment that LGBTQ students find themselves contending with in their universities.

While existing literature on LGBTQ diversity and inclusion in higher education has identified the key challenges facing LGBTQ students, it has largely failed to engage with the specific experiences of Asian universities. We attempt to address this lacuna in the scholarship. This is important for three reasons. Firstly, as higher education expands in Asia, there needs to be a greater focus not only on the quality of education but also the experiences of students. Without a safe and affirming environment for all students, effective learning cannot take place. Secondly, LGBTQ issues are often viewed as undesirable foreign, specifically Western, practices in many Asian societies that are at odds with "Asian values." This poses a challenge to educators and university administrators navigating this complex socio-political landscape. Thirdly, LGBTQ students in Asia may experience their gender and sexual identities differently from their peers in Anglo-American settings as a result of how social institutions such as family and adulthood are culturally conceived.

Before we proceed and as others in this volume have emphasized, it is both difficult and disingenuous to speak about Asia as if it were a coherent conceptual or geographical category. The sheer diversity in history, culture, geography and politics not merely across the entire region but even between two neighboring countries makes it nearly impossible to generate any useful generalization about the whole continent. In particular, the socio-legal landscape relating to LGBTQ issues is especially diverse; while Taiwan has achieved marriage equality and India and Bhutan have repealed laws that criminalize same-sex intimacy, more than twenty other Asian countries still criminalize it. ${ }^{6}$ Nevertheless, in exploring Asian perspectives on the issues facing LGBTQ students in higher

${ }^{5}$ Lucas Ramon Mendos, State-Sponsored Homophobia Report 2019 (Geneva: ILGA, 2019).

6 “Taiwan Legalises Same-Sex Marriage in First for Asia," The Straits Times, May 18, 2019; "India's Top Court Lifts Ban on Gay Sex in Landmark Ruling," The Straits Times, September 6, 2018; and "Bhutan LGBT Community Celebrates After Homosexuality Is Decriminalised," The Straits Times, June 8, 2019. 
education, we believe that there are some common issues and themes that affect the regions which are worth examining. More fundamentally, we hope that this chapter demonstrates to educators that context is critical in approaching something as politically controversial and culturally sensitive as LGBTQ issues in the university setting.

As we will briefly outline later in this chapter, in countries where extensive research has been conducted, the challenges that LGBTQ students face are well-documented in terms of the relative invisibility of sexual and gender diversity on campus and the lack of targeted support resources. ${ }^{7}$ This chapter builds on existing scholarship by examining how these challenges manifest themselves in Asian universities where particular cultural and historical factors may exacerbate negative and potentially hostile attitudes toward LGBTQ identities and expressions. Unlike universities in North America and Europe, which are often already committed to LGBTQ inclusion in principle, most universities in Asia can either be described as hostile or ambivalent toward LGBTQ students. The strategies that may work in the former contexts may therefore either be impossible or extremely unfeasible in Asia. In this chapter, we use various case studies to develop a theoretical framework for understanding how universities in Asia, especially in countries with restrictive laws and unaccepting cultural attitudes, can become more affirming institutions for LGBTQ students as a result of factors such as student activism and globalization.

We develop this framework to categorize the different types of Asian universities in terms of their institutional approaches toward LGBTQ inclusion. We identify three types of approaches: affirmation, ambivalence, and hostility. This framework allows educators and administrators to better strategize their advocacy for LGBTQ inclusion as well as the implementation of culturally appropriate programs that best support LGBTQ students in their campuses. We focus especially on institutional approaches toward LGBTQ inclusion because the institution itself is often the key

${ }^{7}$ See, for instance, Sue Rankin, Genevieve Weber, Warren Blumenfeld, and Somjen Frazer, 2010 State of Higher Education for Lesbian, Gay, Bisexual \& Transgender People (Charlotte: Campus Pride, 2010); Susan B. Marine and D. Chase J. Catalano, "Engaging Transgender Students on College and University Campuses," in Student Engagement in Higher Education: Theoretical Perspectives and Practical Approaches for Diverse Populations, edited by Stephen J. Quaye and Shaun R. Harper (New York: Routledge, 2014), 135148; and Dafina-Lazarus Stewart and Mary F. Howard-Hamilton, "Engaging Lesbian, Gay, and Bisexual Students on College Campuses," in Student Engagement in Higher Education, 121-134. 
obstacle to fostering a more diverse university community in the Asian context as a result of social and political factors. Consequently, while individual educators may attempt to incorporate inclusive strategies in their pedagogy, they may face significant challenges in doing so. It is therefore crucial for those concerned with the well-being and learning of LGBTQ students to focus not only on specific teaching or student engagement strategies but also consider how they can effectively advocate for LGBTQ inclusion at an institutional level. In addition, while we focus largely on LGBTQ students, the institutional approach of a university also affects the experiences of LGBTQ staff and faculty in terms of whether they may face violence or discrimination or come out as LGBTQ on campus; a case involving the suicide of a librarian working at the Myanmar Imperial University illustrates the real impact that a hostile university environment can have on LGBTQ staff as well. ${ }^{8}$

The rest of this chapter proceeds as follows. Section "Challenges Facing LGBTQ Students in Asia" provides a brief context on the challenges facing LGBTQ students in Asia both within the university setting and more broadly in Asian societies. Section "Three Types of Institutional Approaches Toward LGBTQ Inclusion in Asia" outlines three types of institutional approaches toward LGBTQ students that can be found in Asia: hostility, ambivalence, and affirmation. Section "Engendering Affirmation Toward LGBTQ Students in Asian Universities" considers the factors that influence how universities can move from hostility to affirmation and the role that students, faculty, and administrators can play in engendering this institutional shift. Section "Pedagogical Strategies for Educators Working with LGBTQ Students or LGBTQ-Related Issues in the Classroom" discusses some strategies that educators may adopt in their pedagogy or curriculum design to better engage with LGBTQ students and LGBTQ-related subjects in the classroom. We conclude in Section "Conclusion and Future Directions" with a brief discussion on the broader impact that LGBTQ inclusion in higher education can have on Asian societies.

8 "Gay Myanmar Man Posts Facebook Bullying Note Before Taking Life," New Straits Times, June 25, 2019, https://www.nst.com.my/world/2019/06/499097/gaymyanmar-man-posts-facebook-bullying-note-taking-life. 


\section{Challenges Facing LGBTQ Students in Asia}

The challenges that LGBTQ students face in Asia are not dissimilar to those that LGBTQ students face elsewhere. According to Schueler, Hoffman, and Peterson, the four main challenges that LGBTQ students face are invisibility, conflicting social identities, homophobia, and a dominant heteronormative culture. ${ }^{9}$ These issues are not unique to the university environment but particularly affect LGBTQ students' identity formation, personal development, and academic engagement as young adults.

\section{Invisibility and the Silence of Sex}

Invisibility is defined as the absence of positive and visible role models for LGBTQ students among faculty, staff, and administrators as well as a lack of support resources that cater to these students. In Asian societies, this is worsened by strong cultural taboos surrounding sex and intimacy where it is considered unprofessional and unacceptable for faculty, staff, and administrators to discuss or share their personal lives, whether heterosexual or otherwise. ${ }^{10}$ Institutionally, because there are also often little to no support resources relating to sexual or reproductive health generally, it may be even harder to advocate for support resources targeted specifically at LGBTQ students. This is troubling because a survey conducted among over 3000 university students in five Southeast Asian countries highlighted the need to prioritize LGBTQ students who were disproportionately affected by mental health issues. ${ }^{11}$

\footnotetext{
${ }^{9}$ Schueler, Hoffman, and Peterson, "Fostering Safe, Engaging Campuses for Lesbian, Gay, Bisexual, Transgender, and Questioning Students," in Student Engagement in Higher Education: Theoretical Perspectives and Practical Approaches for Diverse Populations, edited by Shaun R. Harper and Stephen J. Quaye (New York: Routledge, 2010), 61-80.

${ }^{10}$ Marwaan Macan-Markar, "Asian Cultural Taboos Hide Links Between Sex and HIV/AIDS," Malaysiakini, July 11, 2002, https://www.malaysiakini.com/opinions/ 21679. See also Zhang Liying, Li Xiaoming, and Iqbal H. Shah, "Where Do Chinese Adolescents Obtain Knowledge of Sex? Implications for Sex Education in China," Health Education 107, no. 4 (2007): 351; Shantha Sankaranarayan, Eknath Naik, P. S. N. Reddy, G. Gurunani, Karuna Ganesh, Kailas Gandewar, K. P. Singh, and S. H. Vermund, "Impact of School-Based HIV and AIDS Education for Adolescents in Bombay, India," Southeast Asian Journal of Tropical Medicine and Public Health 27, no. 4 (1996): 692.

${ }^{11}$ Karl Peltzer and Supa Pengpid, "Minority Stress Among Lesbian, Gay, Bisexual, and Transgender (LGBT) University Students in ASEAN Countries: Associations with Poor Mental Health and Addictive Behaviour," Gender and Behaviour 14, no. 3 (2016): 7806.
} 


\section{Recognizing Different Dimensions of LGBTQ Students' Identities}

Just as students of color or faith in the West may struggle with conflicting identity dimensions, LGBTQ students in Asia similarly struggle with the cultural and religious rejection of their sexual or gender identities. This "double oppression"-in terms of being from a minority ethnic or religious group and being LGBTQ - however may transform into a "triple oppression" in the Asian context, where LGBTQ identities are often derided as a foreign, Western invention. LGBTQ students thus have to grapple not only with cultural and religious tensions but also historical and political ones, where their identities are perceived to be a neo-imperial import that are at odds with traditional "Asian values" and the postcolonial struggle. ${ }^{12}$ Because of these factors, it is unsurprising that homophobia and heteronormativity are particularly thorny issues in many Asian societies. This is especially the case in many Muslim-majority countries, where there are rising trends of Islamic fundamentalism and Islamization. This has led to the troubling trend of criminalization of or enhanced punishments for same-sex intimacy in Malaysia, Indonesia, and Brunei. ${ }^{13}$ Even when there is no explicit threat of violence or discrimination such as in parts of East Asia, parental and social expectations of conformity continue to marginalize LGBTQ students who face prejudice and rejection for being different.

\section{Understanding Different Needs of LGB and TNB Students}

At this point, it is important to note that though they are often combined, the challenges facing transgender and non-binary (TNB) students are often very different from those that lesbian, gay, and bisexual (LGB) students face. This is especially salient in some Asian societies, where attitudes toward non-normative gender identities and expressions may sometimes be more affirming than attitudes toward non-normative sexual orientations and practices. An example is Pakistan, where consensual samesex sexual conduct may attract the death penalty under shariah law but where the historical and cultural role of hijras, who are recognized as

\footnotetext{
${ }^{12}$ For a deeper discussion of the "Asian values" debate in the context of LGBTQ rights, see Po-Han Lee, "LGBT Rights Versus Asian Values: De/Re-constructing the Universality of Human Rights," The International Journal of Human Rights 20, no. 7 (2016): 978.

${ }^{13}$ Mendos, State-Sponsored Homophobia Report 2019, 127.
} 
belonging to a third gender, has led to growing social acceptance and legal protection. ${ }^{14}$ Conversely, in Japan, while many parts of the country have legalized same-sex marriage, ${ }^{15}$ transgender people continue to be forcibly sterilized as part of the policy requirements to correct their legal gender. ${ }^{16}$ It is therefore important to recognize that though they are often spoken of in the same breath, the experiences and needs of LGB students are often significantly different from those of TNB students.

\section{Appropriate Language and Terminology in Context}

Furthermore, within each identity category, there is significant diversity as well. As Stewart and Howard-Hamilton observed, "LGB people are not a monolithic group and the impact of other systems of oppression has prompted the development of communities within communities."17 This has led to different identificatory labels that vary across diverse groups. Though terms like lesbian and gay are globally recognizable, they may not be the most appropriate or familiar terms in certain contexts. ${ }^{18}$ The hijra comes to mind; though it is often (mis)translated as transgender or intersex, the cultural meanings attached to hijra cannot be represented by those other terms. In some cases, similar vocabulary may be utilized but with their own specific meanings and connotations; for instance, Boellstorff described how LGBTQ Indonesians referred to themselves as lesbi, gay or waria, terms which may appear similar to but are distinct from the Western conceptions of lesbian, gay, and transgender identity. ${ }^{19}$ It is therefore crucial that educators familiarize themselves with the relevant

${ }^{14}$ Mendos, State-Sponsored Homophobia Report 2019, 136.

${ }^{15}$ Mendos, State-Sponsored Homophobia Report 2019, 286.

${ }^{16}$ Graeme Reid, Kanae Doi, and Michael Bochenekh, 'A Really High Hurdle': Japan's Abusive Transgender Legal Recognition Process (New York: Human Rights Watch, 2019).

${ }^{17}$ Stewart and Hamilton, "Engaging Lesbian, Gay, and Bisexual Students on College Campuses," 122.

${ }^{18}$ See, for instance, William Leap and Tom Boellstorff, eds., Speaking in Queer Tongues: Globalization and Gay Language (Champaign: University of Illinois Press, 2004).

${ }^{19}$ Tom Boellstorff, "Gay and Lesbi Subjectivities, National Belonging and the New Indonesia," in Women in Indonesia: Gender, Equity and Development, edited by Kathryn Robinson and Sharon Bessell (Singapore: Institute of Southeast Asian Studies, 2002), 92-99. 
language that LGBTQ students may use in their particular communities to better relate to and engage with them.

\section{Diverse Cultural Conceptions of Gender and Sexuality}

It is also important to note that while LGBTQ identities may have become the dominant paradigm by which same-sex desire and practices are understood, this may not be the case in some Asian societies. For instance, because of social, cultural, and religious factors, an Arab man who engages in same-sex sexual activity in his youth may not identify as being gay and may go on to marry a woman and have children. This should not be misapprehended as internalized homophobia or suppression of one's homosexual desires. As Massad emphasizes, traditional Arab sexualities are not founded on the hetero-homo binary that prevails in contemporary imaginations. ${ }^{20}$ Educators should therefore be careful of relying on preconceived or non-native understandings of gender and sexuality that may not resonate with their students.

Given the potential violence and discrimination that LGBTQ students may face in many Asian universities, it is crucial for educators to carefully navigate classroom dynamics to support these students without potentially putting them at risk. Furthermore, educators who teach LGBTQ-related subjects need to contend with the different cultural contexts in Asia where some students may be less comfortable or familiar with these concepts. These issues will be discussed further in Section "Pedagogical Strategies for Educators Working with LGBTQ Students or LGBTQ-Related Issues in the Classroom".

\section{Three Types of Institutional Approaches Toward LGBTQ INCLUSION IN ASIA}

Having discussed the challenges that LGBTQ students in Asia face, this section turns toward the institution of the Asian university. While it is perhaps generally accepted in European or North American universities that LGBTQ inclusion is desirable and beneficial, this is not the case in most Asian universities. We describe three types of institutional approaches toward LGBTQ inclusion. Firstly, the archetypal European or

${ }^{20}$ Joseph A. Massad, Desiring Arabs (Chicago: University of Chicago Press, 2008). 
North American university may be described as an affirming institution that values LGBTQ inclusion. Secondly, most Asian universities may be best characterized as ambivalent toward LGBTQ students in that administrators and their policies do not acknowledge the existence of such diversity and ignore or condone any discrimination that LGBTQ students may face on campus. Finally, at the other end of the spectrum are hostile universities that not only condones discrimination against LGBTQ students but also actively perpetuates violence and discrimination through its faculty, administrators, and policies. Such universities are generally found in societies where harsh laws criminalizing same-sex intimacy exist and attitudes toward LGBTQ persons are extremely negative.

This framework is useful in several ways. Importantly, it situates the three university archetypes along a linear axis, where a hostile university may gradually shift from first being ambivalent to finally being affirming toward LGBTQ students. This institutional shift does not occur in a vacuum; since universities are embedded in the societies that they are located; they are acutely influenced by the prevailing socio-legal landscape. The next section discusses the factors that may engender this institutional shift.

Different strategies may be effective based on the institutional context that educators and administrators are operating in. For instance, an educator operating within a hostile institutional environment may adopt a less overt and resource-intensive strategy to engage with LGBTQ students: organizing a networking event for these students may not be feasible but a small, informal support group meeting might be. This framework thus allows educators and administrators to reflect on and better strategize how they may best support and advocate for LGBTQ students.

This framework thus allows for greater conceptual clarity when discussing Asian universities. The climate at a university in Beijing, China may be very different from one in Dhaka, Bangladesh. By distinguishing between different stages that Asian universities may be at, this framework provides theoretical nuance to the study of LGBTQ inclusion in Asia. Notwithstanding, the descriptions that follow and the table outlining each institutional approach appended at the end of this section are neither exhaustive nor definitive and would benefit from further clarification and development in future scholarship. 


\section{The Affirming University}

The terminal and desired institutional approach toward LGBTQ students, the affirming university is one that recognizes and, as its name suggests, affirms the gender and sexual diversity in the university community. This affirmation manifests itself in both university policy and programming as well as the wider campus culture. In some cases, such affirmation may be mandated by law through the actual implementation on the ground often falls short. For instance, in Taiwan, the Gender Equity Education Act requires schools to "provide a gender-fair learning environment, respect and give due consideration to students, faculty, and staff with different gender, gender temperaments, gender identity, and sexual orientation." 21 It also prohibits schools from discriminating against prospective and current students on the basis of their "gender, gender temperaments, gender identity or sexual orientation." 22 However, a recent study reported gaps in realizing these legal obligations due to various cultural and administrative challenges. ${ }^{23}$

Primarily, an affirming university would have an anti-discrimination policy in place that LGBTQ students-and other students from marginalized communities - can turn to should they experience bullying or discrimination from other students, faculty or administrators. This means that the policy is not only on the books but also actively enforced to protect LGBTQ students from any and all forms of discrimination. Furthermore, the university's housing, healthcare and other policies are LGBTQinclusive and the corresponding departments actively ensure that LGBTQ students feel comfortable seeking support from them. Policies also do not differentiate students based on their sexual orientation; for instance, if housing is available to students who are coupled, it would be available to both heterosexual and same-sex couples. Gender-neutral housing is available to students and they may change their gender markers without having to have amended their legal gender. Policy language is also written using inclusive language that does not perpetuate the gender binary or heteronormativity.

${ }^{21}$ The Republic of China (Taiwan), Article 12, Gender Equity Education Act, 2004.

22 Articles 13 and 14, Gender Equity Education Act.

${ }^{23}$ Ada L. Sinacore, Shu-chu Cha, and Jennifer Ho, "Gender Equity Education Act in Taiwan: Influences on the School Community," International Journal for Educational and Vocational Guidance 19, no. 2 (2019): 293-312. 
Besides that, there are activities and events that are either about or targeted at LGBTQ students. This may include support group meetings, networking events and talks or lectures about LGBTQ-related issues. LGBTQ students are visible in the university community, either through the establishment of official student groups or campus committees focusing on LGBTQ inclusion, and there are openly LGBTQ or LGBTQaffirming faculty or administrators to whom students can turn for support and mentorship.

Together, such policies and programming foster an affirming campus environment. LGBTQ students generally feel comfortable about disclosing their gender or sexual identities if they so choose and can seek support from various channels. Educators are free to teach about LGBTQ-related issues in the classroom as well because students are comfortable and familiar with them.

Examples that approximate this archetype include Yale-NUS College in Singapore and New York University (NYU) Shanghai. Both these institutions have established policies like those discussed above that are like their affiliated American universities which are known for their strong affirmation of LGBTQ diversity. Bangkok University has also put in place affirming policies such as a trans-inclusive uniform policy and Thammasat University has included discussions on gender identity led by a transgender lecturer in a mandatory course for all incoming first-year students. ${ }^{24}$ Hong Kong University (HKU) introduced gender-neutral bathrooms in 2016 and runs a Sexual Diversity Network that aims to increase awareness of "the needs of people from varied sexual orientations" and advocate sexual diversity on campus. ${ }^{25}$

${ }^{24}$ Jonathan Head, "Bangkok University Transgender Students Get New Uniform Rules," BBC News, June 9, 2015, https://www.bbc.com/news/world-asia-33060185; "Thai University Introduces Mandatory Class on Transgender Issues," TEAK Trans Empowerment, October 10, 2017, https://teak.site/thai-university-introduces-mandatoryclass-on-transgender-issues/.

${ }^{25}$ Cannix Yau, "University of Hong Kong Accused of Trying to Brainwash Campus with Unisex, LGBT-Friendly Toilets," South China Morning Post, September 2, 2016, https://www.scmp.com/news/hong-kong/education-community/article/ 2013151/university-hong-kong-accused-trying-brainwash; "Diversity and Social Inclusion," CEDARS-CoPE, accessed June 4, 2019, https://wp.cedars.hku.hk/web/cope/? $\mathrm{p}=849$. 


\section{The Ambivalent University}

The ambivalent university is characterized by the absence of any effective policies or programming that affirm LGBTQ diversity on its campus. There is therefore little to no specialized services supporting LGBTQ students because the university does not explicitly recognize the existence of gender and sexual diversity. For instance, according to one article, in Hong Kong, counselling services that are provided in universities do not actively reach out to LGBTQ students and counsellors often lack experience and expertise in dealing with LGBTQ students. ${ }^{26}$

In some cases, administrators are willing to provide support to LGBTQ students on a discretionary basis though this is not usually made known publicly. For instance, according to research conducted by the InterUniversity LGBT Network in Singapore, the two main public universities that provide on-campus housing can offer transgender students housing in a mixed-gender arrangement if students make a special request on the basis of their gender identity. ${ }^{27}$ However, this may not be entirely appropriate as it places the burden on transgender students to disclose their identities to university administrators.

At an ambivalent university, though discrimination may be prohibited in the university's code of conduct, there is no clear process for aggrieved students to seek recourse. Most cases of discrimination thus often go unreported. Where a case is reported, perpetrators of discrimination are often let off with a slap on the wrist, signaling to LGBTQ students that their safety and wellbeing are not of utmost priority to the university.

For instance, in 2014, a Malay Studies professor at the National University of Singapore (NUS) published a Facebook post referring to lesbianism as "cancers" and "social diseases." 28 In response, the University Provost sent a circular to all members of the university, stating that the

${ }^{26}$ Stuart Heaver, "LGBT Students Face so Much Prejudice in Hong Kong They're Afraid to Reveal Their Sexuality," South China Morning Post, November 29, 2018, https://www.scmp.com/lifestyle/family-relationships/article/2175396/lgbtstudents-face-so-much-prejudice-hong-kong-theyre.

${ }^{27}$ Rachel Yeo, "Trans* In College: A Handbook for Transgender Students in Singapore's Universities," Inter-University LGBT Network, https://interunilgbt.wixsite.com/ interunilgbt/books-resources.

${ }^{28}$ Pearl Lee, "NUS Prof's Comments on Lesbians Spark Protests from Past and Present Students," The Straits Times, February 28, 2014, https://www.straitstimes.com/ singapore/nus-profs-comments-on-lesbians-spark-protests-from-past-and-present-students. 
university "embraces faculty, staff and students regardless of gender, ethnicity, religion, nationality, political beliefs or sexual orientation." $29 \mathrm{He}$ added that he had counselled the faculty member in question, who merely acknowledged that his posts reflected "poor judgment in the tone and choice of words"; there was no acknowledgement that his views were discriminatory nor were any measures taken to ensure LGBTQ students can feel safe should they decide to take this professor's classes in the future.

Additionally, while LGBTQ students may informally organize themselves to provide peer support or advocate for themselves, they are not funded by or recognized by the ambivalent university. An example is UP Babaylan which is the first Filipino student LGBT group at the University of the Philippines, Diliman campus in Quezon City, Philippines. Similarly, though students in various Taiwanese universities have established LGBTQ groups since the 1990s, with the first being NTU GayChat at the National Taiwan University (NTU) in 1993, student activists report facing significant challenges registering and operating their groups at institutions that are funded by or affiliated with religious groups such as the Fu Jen Catholic University. ${ }^{30}$

\section{The Hostile University}

At the other end of the spectrum are the hostile universities, which are openly antipathetic toward LGBTQ students. Students who are perceived to be LGBTQ experience bullying and discrimination, that are often sanctioned by the university. An example is the "Back to Fitrah" event at the Universiti Sains Malaysia (USM), a contest organized by the USM Muslim Students Association to assist students with "disorders in sexual orientation return to their natural instincts." 31 Similarly, at Indonesia's Andalas University in Padang, West Sumatra, students were required to

${ }^{29}$ June Yang, "NUS Professor Acknowledges 'Poor Judgment' in Posts on Sexuality," Today Singapore, March 5, 2014, https://www.todayonline.com/singapore/nus-professoracknowledges-poor-judgement-posts-sexuality.

${ }^{30}$ Eddy Chang, "Taipei Watcher: LGBT Clubs Should Be Allowed to Come Out of the Closet," Taipei Times, September 27, 2015, http://www.taipeitimes.com/News/feat/ archives $/ 2015 / 09 / 27 / 2003628678 / 1$.

31 "Forum Not to Change LGBTs but to Foster Goodwill, Says USM Student Body," The Sun Daily, April 5, 2018, https://www.thesundaily.my/archive/forum-not-changelgbts-foster-goodwill-says-usm-student-body-HUARCH537814. 
sign a form declaring that they were not openly LGBTQ. The university's chancellor defended such a policy on the basis that the institution had the right to discriminate because of religious teachings. ${ }^{32} \mathrm{He}$ added that if an enrolled student is found to be LGBTQ, the university would "rehabilitate" them before expelling them.

For transgender and gender non-conforming students, many universities also have strict uniform or hair policies. In both Thailand and the Philippines, university students are expected to dress and present themselves according to specific requirements. For instance, Human Rights Watch found that many transgender students in the Philippines were suspended or even expelled for "cross-dressing." 33 There have also been multiple reports of transgender students being denied the ability to dress according to their gender identity and forced to wear the uniform or graduation gown of the sex they are assigned at birth. ${ }^{34}$

Based on the Table 9.1 outlined below, we compare two universitiesthe National University of Singapore and Hong Kong University-to consider their institutional approaches toward LGBTQ inclusion.

\section{Case Study 1: Ambivalent University}

National University of Singapore

There is no anti-discrimination policy protecting LGBTQ students. The official university policy refers to "Singapore nondiscrimination laws and the relevant Singapore government policies," which do not explicitly address sexual orientation, gender identity or expression. ${ }^{35}$ Though the Student Code of Conduct states that "students should avoid... the purveying or dissemination of pejorative viewpoints along sectarian lines (including but not limited to issues on race, language, religion, gender, sexuality,

32 "Indonesian University Refuses to Accept LGBT Students, Citing Protection of Their 'Rights'," Coconuts Jakarta, May 3, 2017, https://coconuts.co/jakarta/lifestyle/ indonesian-university-refuses-accept-lgbt-students-citing-protection-rights /

${ }^{33}$ Human Rights Watch, 'Just Let Us Be': Discrimination Against LGBT Students in the Philippines (New York: Human Rights Watch, 2017).

34 "University denies trans Student's Right to Wear Female Uniform; Reflects Discrimination Faced by Thailand's LGBT Community," Prachatai, January 22, 2019, https://prachatai.com/english/node/7887; Melalin Mahvongtrakul, "Uniform Justice," Bangkok Post, February 6, 2017, https://www.bangkokpost.com/lifestyle/social-andlifestyle/1193641/uniform-justice/feed/. 


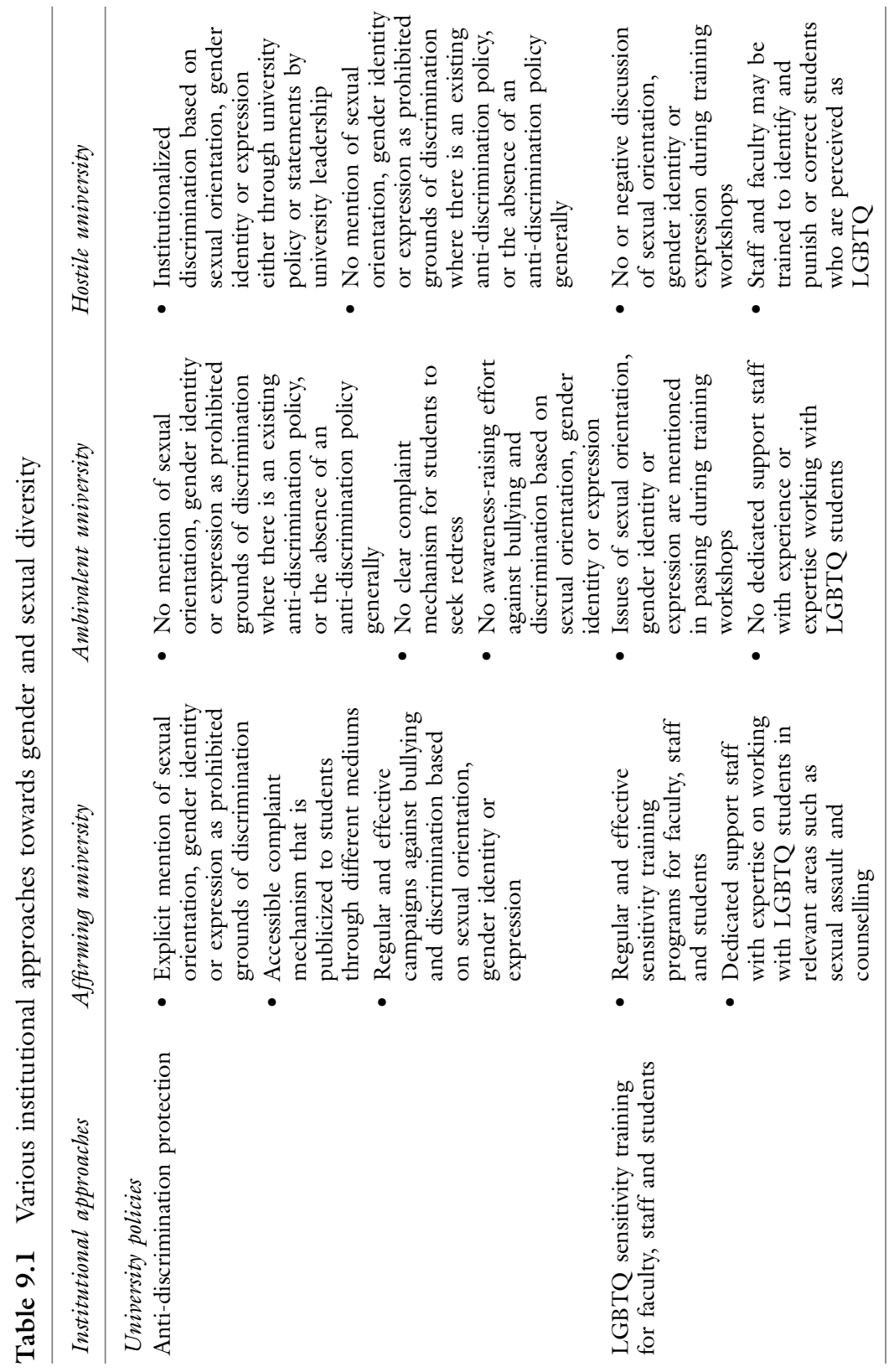




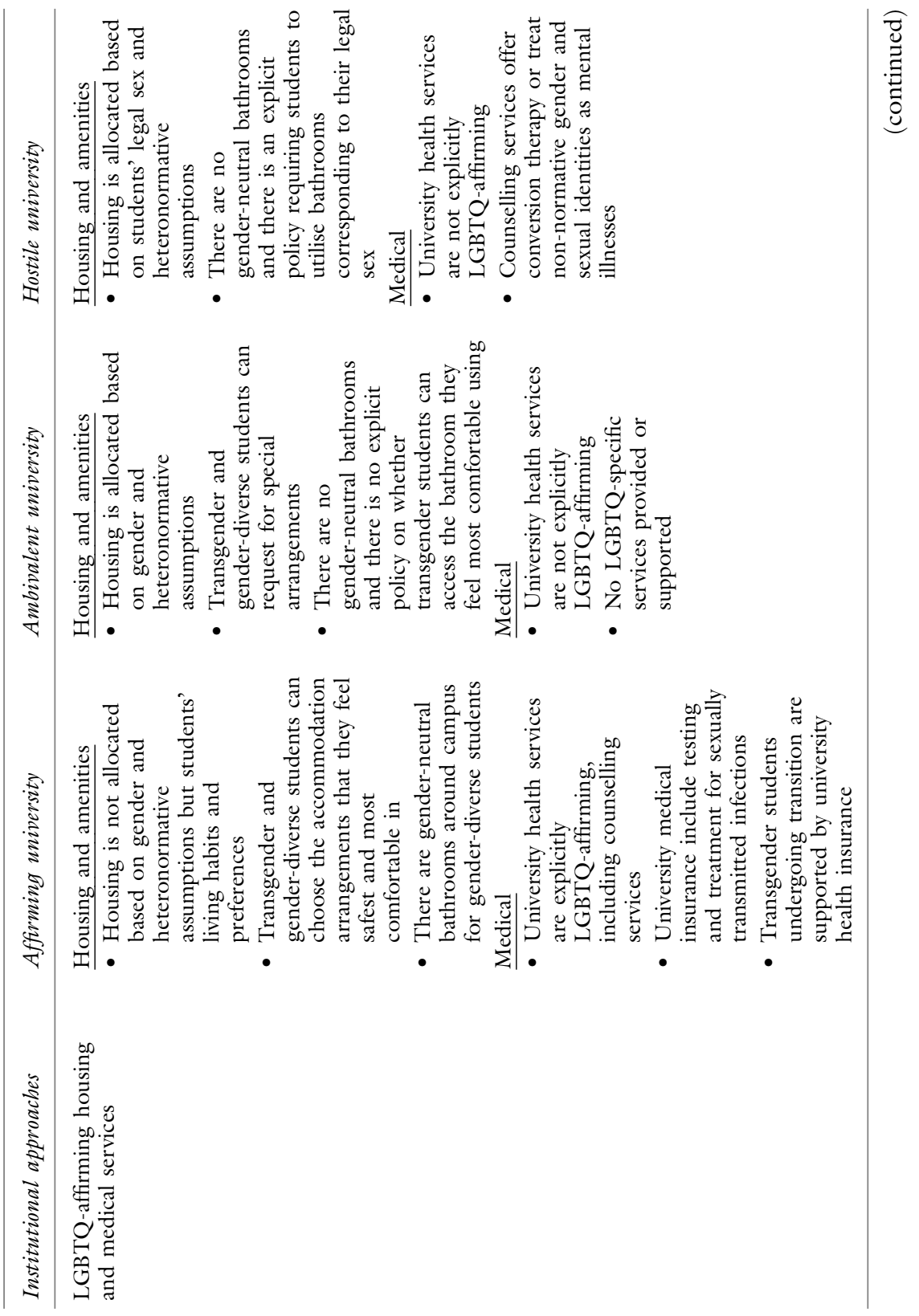




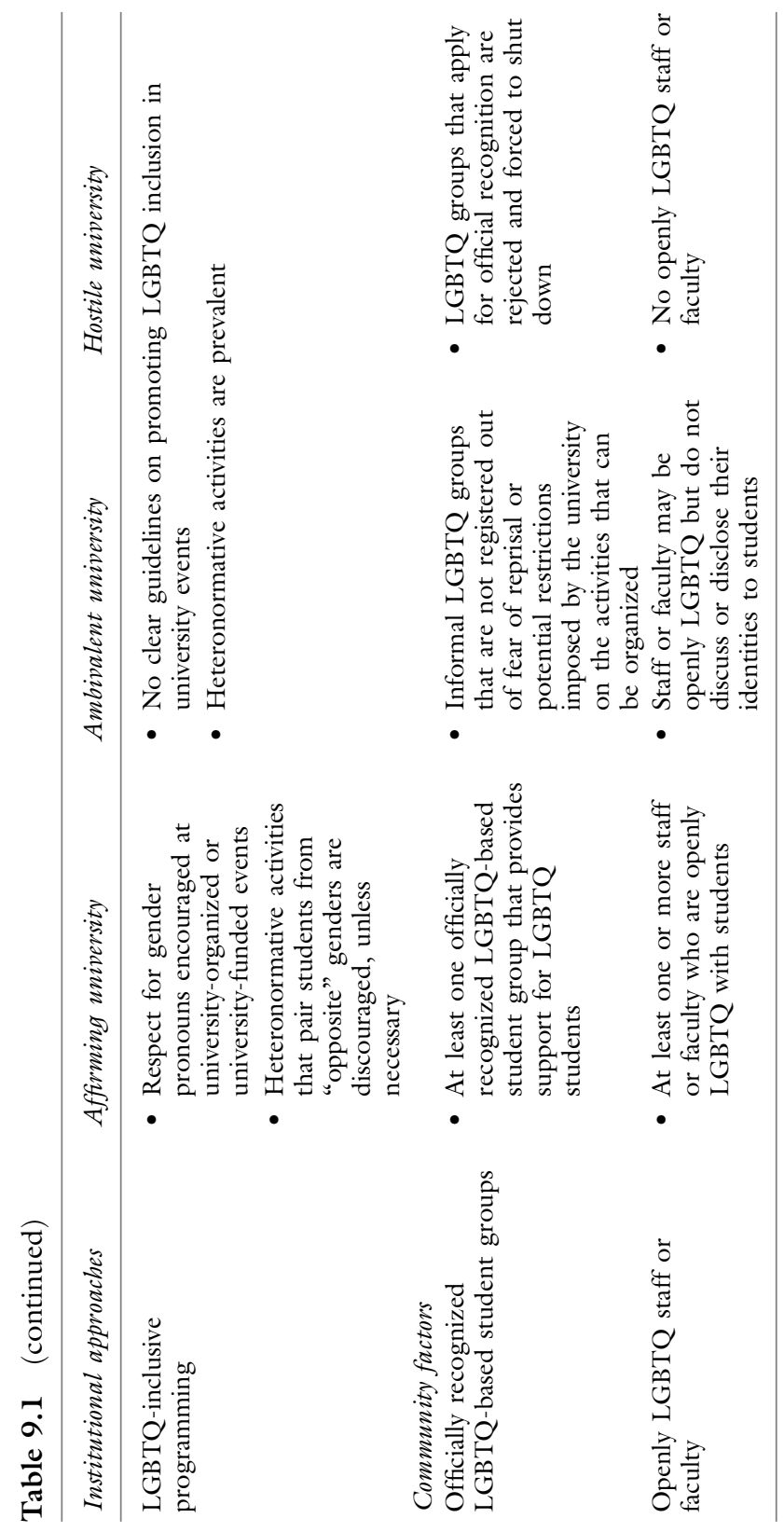


age, nationality)," it does not provide for any form of sanction against students who do so. 36

There are also no LGBTQ-specific training programs for staff or faculty. Though a university administrator has expressed a willingness to accommodate transgender students with respect to housing, it remains on a discretionary basis and there is no medical support for transgender students. ${ }^{37}$ There are no specific guidelines addressing LGBTQ inclusion for university events or programs.

There is no university-wide LGBTQ student group, though some groups have been set up in residential colleges. While there are some openly LGBTQ faculty or staff, they generally do not discuss or disclose their LGBTQ identities to students.

\section{Case Study 2: Affirming University}

Hong Kong University

The Equal Opportunity Unit of the university explicitly forbids sex discrimination and harassment on the grounds of sexual orientation. ${ }^{38}$ It also provides an online form and a set of formal procedures for the investigation of complaints. ${ }^{39}$

Though there does not appear to be LGBTQ-specific trainings, the Equal Opportunity Unit and the Centre of Development and Resources for Students (CEDARS) both provide some education resources on fostering an LGBTQ-inclusive campus environment. ${ }^{40}$ The Counselling and Person Enrichment Section (CoPE) of CEDARS also explicitly affirms LGBTQ students on its website and runs a Sexual Diversity Network, which focuses on increasing awareness on the needs of people from varied sexual orientations and promoting a sensitive counselling service and support network. ${ }^{41}$ The university has also introduced gender-neutral bathrooms. ${ }^{42}$

The university also recognizes the Queer Straight Alliance, which is a network of LGBTQ students, staff and allies across campuses in Hong

35 "Legal Information \& Notices," National University of Singapore, http://www.nus. edu.sg//legal-information-notices\#nondiscrimination.

36 "Code of Student Conduct," NUS Office of Student Affairs, http://www.nus.edu. $\mathrm{sg} / \mathrm{osa} /$ resources/code-of-student-conduct.

${ }^{37}$ Yeo, "Trans* In College." 
Kong. ${ }^{43}$ There is also at least one openly LGBTQ faculty, lecturer Brenda Alegre who joined the university to teach a course on gender and sexuality. 44

\section{Engendering Affirmation Toward LGBTQ Students IN ASIAN UNIVERSITIES}

The previous section demonstrates that many Asian universities remain either ambivalent or hostile toward LGBTQ students. Such approaches are unsurprising as they mirror the wider socio-legal environment that the universities are embedded in. In countries where same-sex intimacy remains criminalized, it is difficult for any university to adopt an affirming approach toward LGBTQ students without exposing itself to potential backlash for condoning or encouraging illegal activities. Even in societies without such laws, hostile socio-cultural attitudes similarly inhibit the ability of universities to address this issue. In some cases, administrators themselves may be prejudiced against LGBTQ students.

How then can educators support their institutions in adopting a more affirming approach toward LGBTQ students? We suggest that there are

\footnotetext{
38 "Policy Statement," Equal Opportunity Unit, http://www.eounit.hku.hk/en/aboutus/policy-statement.

39 "Online Form," Equal Opportunity Unit, http://www.eounit.hku.hk/en/ complaints-enquiries/online-form; "Procedures," Equal Opportunity Unit, http://www. eounit.hku.hk/en/complaints-enquiries/procedures.

40 "Student Orientation Guidelines," Equal Opportunity Unit, http://www.eounit.hku. hk/en/guidelines/student-orientation-guidelines; "How Can I Contribute in Promoting a LGBT-Friendly Environment on Campus?," CEDARS-CoPE, https://dmp.cedars.hku. hk/watch_video.php?v=RAXRKW1931YW.

${ }^{41}$ CEDARS-CoPE, "Diversity and Social Inclusion."

${ }^{42}$ Yau, "University of Hong Kong Accused of Trying to Brainwash Campus with Unisex, LGBT-Friendly Toilets."

43 CEDARS-CoPE, "Diversity and Social Inclusion."

${ }^{44}$ Kylie Knott, "Transgender Lecturer in Hong Kong on Her Fight to Be Accepted by a Conservative Society, and Her Fear of the Police," South China Morning Post, January 20, 2018.
} 
three main factors that can influence the institutional shift toward affirmation: an affirming socio-legal landscape, the globalization of higher education, and student activism.

\section{Affirming Socio-Legal Landscape}

As noted earlier, the wider socio-legal environment that universities operate in have a significant impact on the campus climate. Regardless of how much educators may try to foster an inclusive classroom environment, the lived realities of LGBTQ students outside of the classrooms will invariably affect the latter's learning and academic performance. It is therefore crucial for educators to consider how they can support LGBTQ students beyond the classroom.

An example is the active role of prominent academics in campaigning for the decriminalization of male same-sex intimacy in Singapore. Many professors and university administrators came out publicly as lead signatories to a petition calling for the repeal of Section 377A of the Penal Code, which punishes gay and bisexual men with up to two years' imprisonment for "acts of gross indecency." 45

Such public support for legal change however should be approached carefully. There are different ways by which educators can advocate for safer and more inclusive laws for their LGBTQ students. In some cases, if an educator is non-native and comes from the Global North, being overly vocal about these topics may reinforce the notion that LGBTQ issues are "Western" or "foreign." Instead, they should consider playing a more supportive role, by assisting or encouraging colleagues or university leaders who are native or from the region to speak up, which would be especially powerful in fostering attitudinal change within the community. Educators should thus strategically consider whether they are likely to be more effective in fostering a more LGBTQ inclusive campus by being on the frontline of advocacy or in working behind the scenes with other faculty, staff or students.

45 "Who We Are," Ready4Repeal, accessed June 6, 2019, from https://ready4repeal. com/who. 


\section{Globalization of Higher Education}

The international movement of people, institutions and ideas in the industry of higher education may encourage universities to adopt a more affirming approach toward LGBTQ students. Increasingly, more international universities are setting up satellite campuses in Asia and there is also an increasing number of collaborations with Asian universities to develop new academic programs or research centres. This presents an opportunity for academics and administrators to share affirming policies and approaches from their parents or previous institutions through these collaborations. Furthermore, it is in the interests of universities to become more LGBTQ-affirming to avoid the potential brain drain of talented students who are becoming increasingly mobile as well.

Nevertheless, the impact of the globalization of higher education may be limited due to the perception that such policies are "Western" and not applicable to the Asian context. It is therefore crucial that educators looking to propose the adoption of affirming policies do so in a strategic manner that will not invoke the specter of Western neo-imperialism. For instance, they should collaborate with local colleagues or students to increase the acceptability of such policies among the larger university community.

\section{Student Activism}

Finally, a major factor influencing the institutional shift toward affirmation comes from LGBTQ and allied students themselves who advocate for more affirming policies and programs. In several countries, students have set up groups to facilitate collective organizing and mutual support. This includes groups such as the Inter-University LGBT Network in Singapore, Action-Q in Hong Kong and UP Babaylan in The Philippines. There are however several risks and challenges that student activists may face in the course of their advocacy.

Clearly, many LGBTQ student groups have faced significant challenges in registering their groups with their university. This is usually the first step toward gaining recognition and resources, without which groups would struggle to recruit members and organize activities. Furthermore, there may be additional challenges in recruitment as students who are not open about their identities may fear the risk of being outed to other students, administrators or their families. As a result, groups find it doubly 
difficult to organize and strategize effectively as they lack the members to operate efficiently.

Moreover, the advocacy of LGBTQ student groups may provoke backlash from other student groups or the public. This may severely impede any progress on policy change and increase the risk of violence and discrimination against LGBTQ students. Thirdly, because of the risks that advocacy may pose, internal disagreements may arise among LGBTQ students in these groups as to whether they should focus on support and networking or advocacy. Some student organizers may prefer to focus on providing support to other LGBTQ students by creating a safe and affirming space that does not otherwise exist. However, conducting advocacy threatens the safety of that space due to the increased visibility and attention on the group and this may deter more vulnerable students from seeking support. Thus, the fracturing of these already-small communities may further hamper the effectiveness of any advocacy efforts.

Educators can offer their support and allyship to these student groups either formally or informally, depending on the context within which they are operating. This can include providing financial support or campus spaces to organize activities that students in unregistered groups may lack and organizing other faculty and administrators to support the students' advocacy efforts. For instance, in relation to the incident involving the NUS professor who had made homophobic comments about lesbian women, over eighty faculty from the same university published a forum letter in the national newspaper condemning his views. ${ }^{46}$ This public statement represented a powerful message to LGBTQ students that there were educators who were willing and ready to stand up to protect them from prejudice. At the same time, it also sent a signal to the university community at large that discriminatory behavior would not be tolerated by a sizeable proportion of educators.

${ }^{46}$ Khoo Hoon Eng, "Sending Wrong Signal on Tolerance," The Straits Times, March 6,2014 . 


\section{Pedagogical Strategies for Educators Working WITH LGBTQ STUDENTS OR LGBTQ-RELATED Issues IN THE ClassRoOM}

While institutional shifts may take years if not decades, educators may adopt strategies in the classroom to foster a more inclusive learning experience for LGBTQ students. This section outlines some of these strategies that both academic and student affairs educators may consider implementing in ambivalent or hostile institutions.

\section{Classroom Experience}

Rather than special strategies targeting LGBTQ students or LGBTQrelated issues in the classroom, common strategies that lead to being inclusive of a diverse student body can be adopted. ${ }^{47}$ Given that institutional support is likely absent, more experienced faculty should invest in the career development of other faculty by organizing workshops to share how common pedagogical principles of learning can be applied to create a LGBTQ-inclusive classroom to foster effective learning for all students. $^{48}$

One of the first steps for any faculty to take is to learn the language and terms used in LGBTQ discourse in the context in which they are working so that they can be sensitive to derogatory terms or slurs. This can ensure their classrooms are safe for LGBTQ students by guiding class discussions in a healthy manner. Another strategy is to outline the importance of respect for diversity at the beginning of the course and referencing specifically diversity based on sexual orientation and gender identity. This can set the tone for class participation in general and signal to LGBTQ students specifically that they are welcome in the class. In particularly hostile environments such as in countries with high rates of violence against

${ }^{47}$ Catherine S. Sanger, "Diversity \& Inclusion in Curriculum and Classroom," Yale-NUS College Centre for Teaching \& Learning, https://teaching.yale-nus.edu.sg/wpcontent/uploads/sites/25/2019/03/Diversity-and-Inclusion-Booklet_02.4.19-Online. pdf, 109.

${ }^{48}$ Michele DiPietro, "Applying the Seven Learning Principles to Creating LGBTInclusive Classrooms," Diversity \& Democracy 15, no. 1 (2012); "LGBTQ Inclusive Curriculum and Classroom Climate," Fordham University, accessed June 4, 2019, https://www.fordham.edu/info/25663/education_and_research_ethics_resources/ 6346/lgbtq_inclusive_curriculum_and_classroom_climate. 
LGBTQ persons, this signal can be conveyed implicitly by referring to sex or gender instead of sexual orientation and gender identity specifically.

\section{Inclusion of LGBTQ + Content in Curriculum}

In terms of curricular content, there should be purposeful inclusion of LGBTQ topics in various courses. By making these topics visible, LGBTQ students and others get the opportunity to engage intellectually across academic fields with topics related to their identities. Students who are part of minority groups (whether by ethnicity, social class, religion and/or sexual orientation) are motivated to learn when their identities are affirmed and included in the curriculum.

For example, an introductory course at Yale-NUS College that is taught to all first-year students invites them to consider the role of social forces in shaping their lives. Through a series of topics that include power, markets, family, social class, race, gender, religion and the state, students get a deeper understanding of how societies are organized and why. Such a course then easily introduces the concept of the diversity of sexual orientation. Another example of such a course at the National University of Singapore is titled "Sexuality in Comparative Perspective" where readings, films and discussions were utilized to cover the sociological nuances of LGBTQ topics. Other ways of engaging students included inviting guest speakers of diverse sexual orientations and gender identities to the class.

While courses from the social sciences and the humanities can easily incorporate issues of identity, social norms and oppressions that include LGBTQ communities, such courses in the curriculum need not be confined to these disciplines. For example, a useful guide to the development of LGBTQ-inclusive curriculum has suggestions for inserting LGBTQ content into subjects such as English Language, Arts, Literature, History, Social Studies, Science, and Mathematics. ${ }^{49}$

Even statistics courses can incorporate LGBTQ material, thus empowering students to learn statistics effectively at the same time as exploring the nuances and complexity of LGBT issues. ${ }^{50}$ At Carnegie Mellon University, Michele DiPietro used the theme of sexual orientation to teach the

${ }^{49}$ GLSEN, "Developing LGBT-Inclusive Classroom Resources," https://www.glsen. org/sites/default/files/LGBT\%20incl\%20curr\%20guide.pdf.

${ }^{50}$ DiPietro, "Diversity Content as a Gateway to Deeper Learning: The Statistics of Sexual Orientation," Diversity and Democracy 12, no. 3 (2009). 
concepts normally covered in an introductory statistics course. For example, the question of how many people are LGBT introduced the concepts of sampling and estimating proportions. Since many LGBT people will not self-identify in surveys, the question also raised the problem of bias and how one can identify, reduce, or estimate it. Similarly, the "nature versus nurture" question introduced hypothesis testing. Data from specific studies then introduced the correct use of various tests (T-test, ANOVA, Chi-Square).

\section{Visibility of LGBTQ Faculty and Allies}

Where LGBTQ faculty or staff are visible in the campus community, they may pose as positive role models to LGBTQ students who may otherwise have never encounter other LGBTQ people who are working adults. Furthermore, their visibility may have an educative effect on the campus community in general which can help to foster a more inclusive environment and reduce instances of discrimination or prejudice that LGBTQ students may face. An example is Aisha Mughal, who was the first openly transgender lecturer at Quaid-e-Azam University in Islamabad, Pakistan. ${ }^{51}$ The report noted that her employment signaled to the university community as well as society at large that "transgender [persons], with proper education and enlightenment, can prove to be contributing citizens of society, just like any other individual."

In addition, faculty who conduct research on LGBTQ communities can increase the visibility of LGBTQ issues in the campus community. For example, at NUS, a professor in the Faculty of Law has published two monographs on the gay movements in Singapore and Myanmar. ${ }^{52}$ By launching these two books with panel discussions chaired by the faculty's Dean, it was a signal to LGBTQ students that the faculty and senior administrators may be willing to create safe spaces for them in academia.

51 "Aisha Mughal First Transgender University Lecturer of Quaid-e-Azam University Islamabad Pakistan," Mehran Post, May 20, 2017, https://www.mehranpost.pk/aishamughal-first-transgender-university-lecturer/.

${ }^{52}$ Lynette J. Chua, Mobilizing Gay Singapore: Rights and Resistance in an Authoritarian State (Singapore: National University of Singapore Press, 2014); Lynette J. Chua, The Politics of Love in Myanmar: LGBT Mobilization and Human Rights as a Way of Life (Stanford: Stanford University Press, 2019). 


\section{Research and Career Resources for LGBTQ Students}

Educators can also foster a more inclusive environment for LGBTQ students by providing resources tailored to them. For instance, in collaboration with supportive administrators and student support staff, faculty can help to compile research and guides to graduate programs that include LGBTQ studies or employers that are LGBTQ-friendly to assist LGBTQ students in identifying suitable opportunities for further studies or employment.

LGBTQ students may also need additional support in career guidance. Educators can consider organizing workshops or consultations to help students prepare for issues that may arise as they seek employment. This can include strategies on how to respond to potentially intrusive interview questions that may force them to disclose their sexual orientation or gender identity, how gender non-conforming students should present themselves in a professional but authentic way as well as how to deal with potentially discriminatory or harassing comments or questions.

In sum, it should be clarified that these strategies are not exhaustive and should be adapted as necessary to the context of one's own institution and its social environment. Furthermore, educators may need to use discretion to avoid exposing any student, staff or faculty to hostile responses outside the classroom or campus. Mutual support is particularly crucial where the institutional environment may be hostile toward gender and sexual diversity and educators should seek out other like-minded colleagues to build solidarity and share their strategies and experiences.

\section{Conclusion ANd Future Directions}

This chapter has sought to explore how educators can foster more inclusive campuses for LGBTQ students at both the institutional and individual levels. We developed a theoretical framework to characterize three types of Asian universities in terms of their institutional approaches toward LGBTQ diversity. In hostile and ambivalent universities, both students and educators face various challenges in promoting LGBTQ inclusion and we have outlined a few strategies by which educators can advocate for safer campuses for LGBTQ students.

Further research should be conducted to better inform educators on how they can best support LGBTQ students in these different contexts. 
We will briefly discuss two issues that deserve attention in future scholarship.

Many hostile institutions are in deeply conservative societies in Asia. While the conflict between LGBTQ rights and religious freedom is playing out in the courts and legislatures across the Atlantic Ocean, this issue has not yet been studied adequately in Asia. Of relevance in the context of higher education is how educators should negotiate and manage differences between students of faith and LGBTQ students in the classroom and on campus generally. This is especially important when the power dynamics between the two groups of students may be significantly skewed in Asian universities compared to European or North American universities, due to differences in both the degree of secularism and the concept of secularity itself. ${ }^{53}$ At the same time, educators cannot appear biased to avoid alienating any particular student or group of students. This raises difficult but important questions that deserve further discussion in the literature. In addition, it may be worth exploring how communities of faith can support and advocate for LGBTQ inclusion; for instance, Catholic student groups in the Philippines have publicly supported a legislation to protect LGBTQ persons from discrimination. ${ }^{54}$

Furthermore, while we have discussed strategies generally, the experiences of transgender and gender-diverse students are likely to differ significantly from lesbian, gay and bisexual (LGB) students. This is especially because their marginalized identities may be more visible than LGB students. Those who choose to transition during university may also require additional support, especially since this is often a period when they live independently from their families. The challenges that these students may face in Asian universities should be examined to better inform educators on how they can best support them during their transition.

In conclusion, while openly hostile administrators in certain universities make it difficult to promote diversity and inclusion for LGBTQ students, it is possible to strategize to encourage ambivalent instructions to become more supportive. We hope that more faculty will be able to implement

${ }^{53}$ See, for instance, Kenneth Dean and Peter van der Veer, eds., The Secular in South, East, and Southeast Asia (London: Palgrave, 2019).

${ }^{54}$ Leonel Abasola, "Catholic Student Councils Back Philippine Gay Rights Bill," UCA News, August 13, 2018, https://www.ucanews.com/news/catholic-student-councils-backphilippine-gay-rights-bill/83043. 
some of the suggested strategies within their own institutions to make them safer and more inclusive spaces for their LGBTQ students.

\section{BIBLIOGRAPHY}

"2 Students form Social Group for Sexual Minorities at Hitotsubashi Univ. After Suicide." The Mainichi, February 28, 2019. https://mainichi.jp/english/ articles/20190228/p2a/00m/0na/004000c.

Abasola, Leonel. "Catholic Student Councils Back Philippine Gay Rights Bill." UCA News, August 13, 2018. https://www.ucanews.com/news/catholicstudent-councils-back-philippine-gay-rights-bill/83043.

Bangkok Times.

Boellstorff, Tom. "Gay and Lesbi Subjectivities, National Belonging and the New Indonesia." In Women in Indonesia: Gender, Equity and Development, edited by Kathryn Robinson and Sharon Bessell, 92-99. Singapore: Institute of Southeast Asian Studies, 2002.

CEDARS-CoPE. "How Can I Contribute in Promoting a LGBT-Friendly Environment on Campus?" Accessed June 4, 2019, from https://dmp.cedars.hku. hk/watch_video.php? $=$ RAXRKW1931YW.

_. "Diversity and Social Inclusion." Accessed June 4, 2019, from https:// wp.cedars.hku.hk/web/cope/?p=849.

Chua, Lynette J. Mobilizing Gay Singapore: Rights and Resistance in an Authoritarian State. Singapore: National University of Singapore Press, 2014.

- The Politics of Love in Myanmar: LGBT Mobilization and Human Rights as A Way of Life. Stanford: Stanford University Press, 2019.

Coconuts Jakarta. "Indonesian University Refuses to Accept LGBT Students, Citing Protection of Their 'Rights'." May 3, 2017. https://coconuts.co/ jakarta/lifestyle/indonesian-university-refuses-accept-lgbt-students-citingprotection-rights/.

Dean, Kenneth, and Peter van der Veer, eds. The Secular in South, East, and Southeast Asia. London: Palgrave, 2019.

DiPietro, Michele. "Applying the Seven Learning Principles to Creating LGBTInclusive Classrooms." Diversity \& Democracy 15, no. 1 (2012).

—. "Diversity Content as a Gateway to Deeper Learning: The Statistics of Sexual Orientation." Diversity and Democracy 12, no. 3 (2009).

Equal Opportunity Unit. "Policy Statement." http://www.eounit.hku.hk/en/ about-us/policy-statement.

—. "Student Orientation Guidelines." http://www.eounit.hku.hk/en/ guidelines/student-orientation-guidelines.

_. "Online Form." http://www.eounit.hku.hk/en/complaints-enquiries/ online-form. 
—. "Procedures." http://www.eounit.hku.hk/en/complaints-enquiries/ procedures.

Fordham University. "LGBTQ Inclusive Curriculum and Classroom Climate." Accessed June 4, 2019, from https://www.fordham.edu/info/25663/ education_and_research_ethics_resources/6346/lgbtq_inclusive_curriculum_ and_classroom_climate.

GLSEN. "Developing LGBT-Inclusive Classroom Resources.” https://www. glsen.org/sites/default/files/LGBT\%20incl\%20curr\%20guide.pdf.

Head, Jonathan. "Bangkok University Transgender Students Get New Uniform Rules." BBC News, June 9, 2015. https://www.bbc.com/news/world-asia33060185.

Human Rights Watch. 'Just Let Us Be': Discrimination Against LGBT Students in the Philippines. New York: Human Rights Watch, 2017.

Leap, William, and Tom Boellstorff, eds. Speaking in Queer Tongues: Globalization and Gay Language. Champaign: University of Illinois Press, 2004.

Lee, Po-Han. "LGBT Rights Versus Asian Values: De/Re-constructing the Universality of Human Rights." The International Journal of Human Rights 20, no. 7 (2016): 978.

\section{Malaysiakini.}

Massad, Joseph A. Desiring Arabs. Chicago: University of Chicago Press, 2008. Mehran Post.

Mendos, Lucas Ramon. State-Sponsored Homophobia Report 2019. Geneva: ILGA, 2019.

National University of Singapore. "Legal Information \& Notices." http://www. nus.edu.sg//legal-information-notices\#nondiscrimination.

New Straits Times.

NUS Office of Student Affairs. "Code of Student Conduct." http://www.nus. edu.sg/osa/resources/code-of-student-conduct.

Peltzer, Karl, and Supa Pengpid. "Minority Stress Among Lesbian, Gay, Bisexual, and Transgender (LGBT) University Students in ASEAN Countries: Associations with Poor Mental Health and Addictive Behaviour." Gender and Behaviour 14, no. 3 (2016): 7806.

Quaye, Stephen J., and Shaun R. Harper, eds. Student Engagement in Higher Education: Theoretical Perspectives and Practical Approaches for Diverse Populations. New York: Routledge, 2014.

Rankin, Sue, Genevieve Weber, Warren Blumenfeld, and Somjen Frazer. 2010 State of Higher Education for Lesbian, Gay, Bisexual \& Transgender People. Charlotte: Campus Pride, 2010.

Ready4Repeal. "Who We Are." Accessed June 6, 2019, from https:// ready4repeal.com/who. 
Reid, Graeme, Kanae Doi, and Michael Bochenekh. 'A Really High Hurdle': Japan's Abusive Transgender Legal Recognition Process. New York: Human Rights Watch, 2019.

Sanger, Catherine S. "Diversity \& Inclusion in Curriculum and Classroom." Yale-NUS College Centre for Teaching \& Learning. https://teaching.yale-nus. edu.sg/wp-content/uploads/sites/25/2019/03/Diversity-and-InclusionBooklet_02.4.19-Online.pdf, 109.

Sankaranarayan, Shantha, Eknath Naik, P. S. N. Reddy, G. Gurunani, Karuna Ganesh, Kailas Gandewar, K. P. Singh, and S. H. Vermund. "Impact of School-Based HIV and AIDS Education for Adolescents in Bombay, India." Southeast Asian Journal of Tropical Medicine and Public Health 27, no. 4 (1996): 692.

Shibun, Nagayasu. "Sexual Minorities in Japan: The Myth of Tolerance." Nippon.com, October 21, 2016. https://www.nippon.com/en/currents/ $\mathrm{d} 00253 /$.

Sinacore, Ada L., Shu-chu Cha, and Jennifer Ho. "Gender Equity Education Act in Taiwan: Influences on the School Community." International Journal for Educational and Vocational Guidance 19, no. 2 (2019): 293-312.

South China Morning Post.

Taipei Times.

"Thai University Introduces Mandatory Class on Transgender Issues." TEAK Trans Empowerment, October 10, 2017. https://teak.site/thai-universityintroduces-mandatory-class-on-transgender-issues/.

The Jakarta Post.

The Republic of China (Taiwan). Gender Equity Education Act. 2004.

The Straits Times.

The Sun Daily.

Today Singapore.

"University denies trans Student's Right to Wear Female Uniform; Reflects Discrimination Faced by Thailand's LGBT Community." Prachatai, January 22, 2019. https://prachatai.com/english/node/7887.

Yeo, Rachel. "Trans* In College: A Handbook for Transgender Students in Singapore's Universities." Inter-University LGBT Network. https://interunilgbt. wixsite.com/interunilgbt/books-resources.

Zhang, Liying, Li Xiaoming, and Iqbal H. Shah. "Where Do Chinese Adolescents Obtain Knowledge of Sex? Implications for Sex Education in China." Health Education 107, no. 4 (2007): 351. 
Open Access This chapter is licensed under the terms of the Creative Commons Attribution 4.0 International License (http://creativecommons.org/licenses/ by $/ 4.0 /$ ), which permits use, sharing, adaptation, distribution and reproduction in any medium or format, as long as you give appropriate credit to the original author(s) and the source, provide a link to the Creative Commons license and indicate if changes were made.

The images or other third party material in this chapter are included in the chapter's Creative Commons license, unless indicated otherwise in a credit line to the material. If material is not included in the chapter's Creative Commons license and your intended use is not permitted by statutory regulation or exceeds the permitted use, you will need to obtain permission directly from the copyright holder.

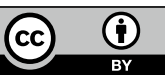

